\title{
Tacaribe Complex Virus
}

National Cancer Institute

\section{Source}

National Cancer Institute. Tacaribe Complex Virus. NCI Thesaurus. Code C129405.

A family of arenaviruses predominantly found in North and South America with family Muridae, subfamily Sigmodontinae as the most common reservoir. Several of these viruses are known to cause severe hemorrhagic disease in humans. 